\title{
The research on express delivery service quality evaluation system based on customer perception
}

\author{
Li Zhou ${ }^{1, \text { a }}$, Lingyao Zhu ${ }^{1, b}$, Yinbo Ma ${ }^{1, \mathrm{c}}$ \\ ${ }^{1}$ School of Information, Beijing Wuzi University, 101149, China \\ aemail: zhoulibit@126.com, bemail: 1052992312@126.com, cemail:yinbo1991@qq.com
}

\section{Keyword: Service Quality, Evaluation Index, Express Delivery Companies}

\begin{abstract}
With economic development, Express delivery companies is growing faster. In the fierce competition, quality of service become more and more important in the Express business, and it gradual becomes the core competitiveness of express delivery companies. This paper evaluates the express delivery quality through the perspective of customer perception and established the assessment indices. Construct services evaluation system according to the characteristics of the courier express industry, we set up indicators in six dimensions: character, function, safety, economy, aging, speed, which make a very important significance in improving service quality of express delivery companies and customer satisfaction.
\end{abstract}

\section{Introduction}

Gronroos (1982) was first proposed the concept of customer perceived service quality [4]. Parasuraman(1985) [1] proposed Quality of Service (SERVQUA) a conceptual evaluation model proposed 10 dimensions of service quality are reliability, responsiveness, competence, access, courtesy, communication, credibility, security , understanding/knowing, tangibility. Parasuraman (1988) reduced from 10 dimensions to five dimensions: tangibles, reliability, responsiveness, access, empathy [2]. In 1992 Cronin and Taylor [3] were reviewed and extended the SERVQUA evaluation model and study the concept and measurement of service quality and the quality of service, the relationship between service quality, customer satisfaction and purchase intent. Most scholars believe that the quality of service is a concept of multi-dimensional multi-attribute. In 2001 Brady and Cronin [5] found that the quality of service model in line with the quality of a third-order factor model, it is related to a different perception of service quality and controllable dimensions: As a result, interaction and environmental quality. These sub-dimensions can be made to improve the perceived quality of service, and the perceived quality of consumers believe to be reliable, responsive and empathy. Many scholars service quality evaluation model expansion and extension, research for courier service quality evaluation, mainly from the traditional concept of the concept of quality of service and quality of service delivery in the field to start, respectively, from the subjective and objective point of view [6], which is the business perspective and a customer perspective two aspects of research in determining the logistics service quality dimensions, the proposed model is representative significance, Jun Zhuo(2013) investigate the determinants that influence the quality of services provided by using mobile devices (mobile services quality) in the Chinese express industry, they drawn six factors from the analysis of data collected: Mobile service empathy, Mobile service confidence, courtesy and willingness, Mobile service reliability and responsive time, Mobile service security, Mobile service tangibility, Mobile service safety [7]. These six factors are expanded in tangibles, reliability, responsiveness, affordable, quality service with perceptual evaluation of five dimensions.

Domestic research on customer perception express service quality evaluation index based on use of AHP, fuzzy comprehensive evaluation, the lack of "respect for the customer" of consideration. In 2014, Liu Zhiqiang combine the Attribute Hierarchical Model and entropy, determine combining weights index, increased the dimension indicators of "customer respect", then make total conversion evaluation use membership algorithm [8]. Performance Analysis (IPA) is a classic service quality evaluation methods, there are three dimensions reliability, guarantee and tangible in SERUAL 
model was confirmed by the majority of China's express delivery service quality research and retained. Responsiveness dimension is modified to be closer to Chinese consumers perceive habits convenience dimension and Zhuang Delin choose to keep the dimension [9] In addition, empathy did not get enough support, and domestic scholars put forward safety and price and other new dimensions. Yuan Jie combine the characteristics and processes of B2C e-commerce logistics service, combine with logistics service quality evaluation model LSQ using SERVQUAL theory, express logistics service quality evaluation system. Reliability was reserved, including aspects about reliability parcel intact, on time and so on. Make the timeliness and responsiveness into reactive, including where the temporal query package for information, order response times and logistics update speed. Responsiveness means customer service in dealing with customers, which the issues raised in a timely manner. Make the assurance into empathy, empathy refers to the attitude of the staff as well as personal qualities, etc. They changed the tangible to convenience, convenience include Germany Shipping method diverse, network coverage. Additional economy, including the economy and reasonable price, service fees and reasonable [10]. Cao Xia et al describes SERVQUAL model of service quality evaluation form the basis for the express industry characteristics, based on the theory of SERVQUAL model, online shopping delivery service process as a contact point, choose modern service facilities, service facilities have attracted nature , clean clothing and outerwear, the company and its facilities and services provided matches the other 24 indicators constructed under the background of online shopping express service quality evaluation system [11].

In summary, research on express service quality evaluation from the concept which based on point of customer satisfaction, with the use of multi-dimensional, multi-angle quality evaluation methods for express service qualitative and quantitative research, has achieved some results and progress as well as has much room for development.

\section{Express Delivery Service Quality Evaluation System}

\section{The principle of building index system}

a. Scientific Principle

Scientific Principles refers to the design and selection of each evaluation must be based on scientific principle, the establishment of various indicators have clear scientific definitions, indicators must not only be based on relevant scientific theory, but also can objectively and truly reflect the quality of service delivery companies. Evaluation should not be too much or too small, it should have a typical representative, to reflect the level of service quality throughout the industry, but also not too little or too simple, there will be a large error evaluation. Data collection and data calculation formula of each index involved should possess a scientific system.

b. Typical principle

Establishment and evaluation must be chosen with a typical representative, can accurately reflect the overall level of quality of service. Setting standards and evaluation of each index weights reflect the needs and express the level of service quality to adapt.

c. Comparable, quantifiable principle

Selection and development of evaluation is to evaluate the different levels of the same nature of service quality, measurement and calculation method chosen must be consistent, each index should be simple, easy to collect data, has a strong practical and operational. Selection and establishment of indicators should consider whether it can be processed into quantitative, mathematical calculations and analysis. Based on the evaluation of the quality of service delivery big data technology require the use of big data technologies and clean data collection, therefore, in the development of various evaluation indicators need to be adjusted and calculated according to the limitation big data technologies.

d. Dynamic principle

Express service is a continuity of existence, to evaluate their quality by a certain time scale can be reflected, so the choice of evaluation to meet the dynamic principle, courier service quality base on monthly units, quarterly units, or year units of data collection and calculation. Data over time 
and constantly updated, so indexes and calculation formula should be established in consistent with the dynamic changes.

e. Comprehensive principle

Evaluation of quality of service delivery is a comprehensive evaluation for the business of express enterprises, therefore should select objective of business capabilities and subjective perception with combination to undertake a comprehensive evaluation. Service quality evaluation should consider all individuality, functionality, security, economic, service attitude evaluation factors, design comprehensive evaluation to evaluate and analyze.

Express delivery service quality evaluation system

Basic research at home and abroad and on the basis of the index construction principle, combined with the characteristics of the courier business enterprises were established evaluation system of six dimensions evaluated 15 indicators from the courier company's business functions and subjective customer perception. As shown in Table 1.

Table 1. Service Quality Evaluation System

\begin{tabular}{|c|c|c|}
\hline $\begin{array}{c}\text { Objective } \\
\text { level }\end{array}$ & Secondary Indicators & Third Indicators \\
\hline \multirow{15}{*}{$\begin{array}{l}\text { Express } \\
\text { Delivery } \\
\text { Service } \\
\text { Quality }\end{array}$} & \multirow{2}{*}{$\begin{array}{l}\text { Individual character } \\
\text { function(K1) }\end{array}$} & Express delivery product diversity(K1.1) \\
\hline & & The emergency response in the peak(K1.2) \\
\hline & $\begin{array}{l}\text { Speediness and } \\
\text { Punctual(K2) }\end{array}$ & Delivery speed(K2.1) \\
\hline & \multirow{4}{*}{$\begin{array}{c}\text { Safety } \\
\text { Specification(K3) }\end{array}$} & Customer privacy protection(K3.1) \\
\hline & & Insurance system(K3.2) \\
\hline & & Transceiver system standardization(K3.3) \\
\hline & & Degree of the goods in good condition(K3.4) \\
\hline & $\begin{array}{l}\text { Economically } \\
\text { priced(K4) }\end{array}$ & Express price(K4.1) \\
\hline & \multirow{2}{*}{ Service attitudeK5 } & Service personnel quality(K5.1) \\
\hline & & Complaint claims service satisfaction(K5.2) \\
\hline & \multirow{5}{*}{$\begin{array}{c}\text { Fast and } \\
\text { comfortable(K6) }\end{array}$} & Express branches convenience degree(K6.1) \\
\hline & & Express information remind(K6.2) \\
\hline & & Convenience of consulting services(K6.3) \\
\hline & & $\begin{array}{l}\text { To make an appointment on time delivery } \\
\text { rate(K6.4) }\end{array}$ \\
\hline & & Convenience of Taking delivery(K6.5) \\
\hline
\end{tabular}

\section{Conclusion}

From the function, timeliness, safety, attitudes, price, comfort six dimensions and metrics established selection, express delivery service quality evaluation subjective evaluation and objective evaluation of the combination of qualitative and quantitative. This paper constructs an evaluation index system, the next step will be set for each indicator specific formulas and data collection methods.

\section{Acknowledgement}

The study is supported by Beijing Key Laboratory of Intelligent Logistics System, (BZ0211), and the project of Beijing Wuzi University Yunhe River scholar, high level cultivation project of Beijing Wuzi University (No. 0541604624), and Beijing Intelligent Logistics System Collaborative Innovation Center, and the project of Research and application of express service certification (CQC). 


\section{References}

[1] A. Parasuraman, Valarie A. Zeithaml, Leonard L. Berry. A Conceptual Model of Service Quality and Its Implications for Future Research [J]. Journal of Marketing.1985, Vol. 49 (4), pp. 41-50.

[2] Valarie A. ZeithamI, Leonard L. Berry, A. Parasuraman. Communication and Control Processes in the Delivery of Service Quality [J]. Journal of Marketing.1988, Vol. 52 (2), pp. 35-48.

[3] J. Joseph Cronin, Jr. and Steven A. Taylor. Measuring service quality: a re-examination and extension [J]. Journal of Marketing.1992, Vol. 56, pp. 55-68.

[4] Gronroos. Service Management and Marketing [M]. Lexington Books, Lexington, MA.

[5] Michael K. Brady, J. Joseph Cronin Jr. Some new thoughts on conceptualizing perceived service quality: a hierarchical approach [J]. Journal of Marketing.2001, Vol.65 (3), pp. 34-49.

[6] Thai, V. V. Logistics Service Quality: Conceptual Model and Empirical Evidence [J]. International Journal of Logistics: Research and Applications. 2013, Vol.16 (2), pp. 114-131.

[7] Jun Zhuo, June Wei, Lai C. Liu, Kai S. Koong, Shengtao Miao. An examination of the determinants of service quality in the Chinese express industry [J]. Electronic Markets.2013, Vol.23 (2), pp. 163-172.

[8] liu zhiqiang, Zhang Cong colourful. Private Courier enterprise service under the perspective of customer perception [J]. Journal of enterprise economy, 2014, 17 (7): 88-92.

[9] ZhuangDeLin Li Jing, summer grass. Express delivery service quality evaluation based on CZIPA method research [J]. Journal of Beijing industry and commerce university, 2015, 30 (2): 48-55.

[10] Yuan Jie. B2C e-commerce construction of express logistics service quality evaluation system research study [J]. Journal of logistic theory, 2015, 12 (6): 86-88.

[11] Cao chardonnay, Li ling. Based on the SERVQUAL model online express delivery service quality evaluation system research [J]. Journal of railway transportation and economy, 2015, 37 (8): 93-98. 